\title{
General Principles of Preclinical Study Design
}

\author{
Wenlong Huang, Nathalie Percie du Sert, Jan Vollert, \\ and Andrew S. C. Rice
}

\section{Contents}

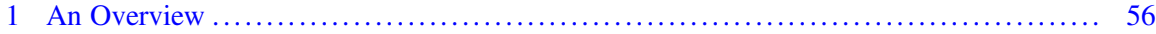

2 General Scientific Methods for Designing In Vivo Experiments ................... 58

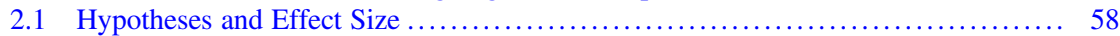

2.2 Groups, Experimental Unit and Sample Size ............................. 58

2.3 Measurements and Outcome Measures ................................. 59

2.4 Independent Variables and Analysis ................................... 60

3 Experimental Biases: Definitions and Methods to Reduce Them $\ldots \ldots \ldots \ldots \ldots \ldots \ldots \ldots \ldots$

4 Experimental Biases: Major Domains and General Principles ...................... 63

5 Existing Guidelines and How to Use Them ................................... 65

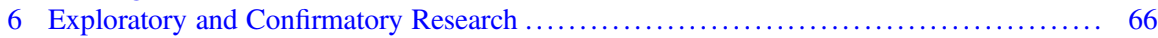

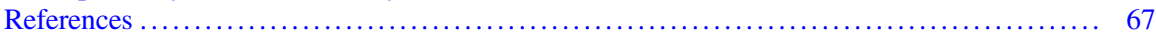

\begin{abstract}
Preclinical studies using animals to study the potential of a therapeutic drug or strategy are important steps before translation to clinical trials. However, evidence has shown that poor quality in the design and conduct of these studies has not only impeded clinical translation but also led to significant waste of valuable research resources. It is clear that experimental biases are related to the poor quality seen with preclinical studies. In this chapter, we will focus on hypothesis testing type of preclinical studies and explain general concepts and principles in
\end{abstract}

W. Huang $(\bowtie)$

Institute of Medical Sciences, School of Medicine, Medical Sciences and Nutrition, University of Aberdeen, Aberdeen, UK

e-mail: w.huang@abdn.ac.uk

N. Percie du Sert

NC3Rs, London, UK

J. Vollert · A. S. C. Rice

Pain Research Group, Faculty of Medicine, Department of Surgery and Cancer, Imperial College London, London, UK 
relation to the design of in vivo experiments, provide definitions of experimental biases and how to avoid them, and discuss major sources contributing to experimental biases and how to mitigate these sources. We will also explore the differences between confirmatory and exploratory studies, and discuss available guidelines on preclinical studies and how to use them. This chapter, together with relevant information in other chapters in the handbook, provides a powerful tool to enhance scientific rigour for preclinical studies without restricting creativity.

\section{Keywords}

Experimental bias $\cdot$ Hypothesis generating $\cdot$ Hypothesis testing · In vivo studies · Preclinical research

This chapter will give an overview of some generic concepts pertinent to the design of preclinical research. The emphasis is on the requirements of in vivo experiments which use experimental animals to discover and validate new clinical therapeutic approaches. However, these general principles are, by and large, generically relevant to all areas of preclinical research. The overarching requirement should be that preclinical research should only be conducted to answer an important question for which a robust scrutiny of the available evidence demonstrates that the answer is not already known. Furthermore, such experiments must be designed, conducted, analysed and reported to the highest levels of rigour and transparency. Assessments of research outputs should focus more on these factors and less on any apparent "novelty".

\section{$1 \quad$ An Overview}

Broadly, preclinical research can be classified into two distinct categories depending on the aim and purpose of the experiment, namely, "hypothesis generating" (exploratory) and "hypothesis testing" (confirmatory) research (Fig. 1). Hypothesis generating studies are often scientifically-informed, curiosity and intuition-driven explorations which may generate testable theories regarding the pathophysiology of disease and potential drug targets. The freedom of researchers to explore such innovative ideas is the lifeblood of preclinical science and should not be stifled by excessive constraints in terms of experimental design and conduct. Nevertheless, in order to subsequently assess the veracity of hypotheses generated in this way, and certainly to justify clinical development of a therapeutic target, hypothesis testing studies which seek to show reproducible intervention effects in relevant animal models must be designed, conducted, analysed and reported to the highest possible levels of rigour and transparency. This will also contribute to reducing research "waste" (Ioannidis et al. 2014; Macleod et al. 2014). Chapter "Resolving the Tension Between Exploration and Confirmation in Preclinical Biomedical Research" of the handbook will deal with exploratory and confirmatory studies in details. This chapter will only focus on general design principles for hypothesis testing studies. We will 


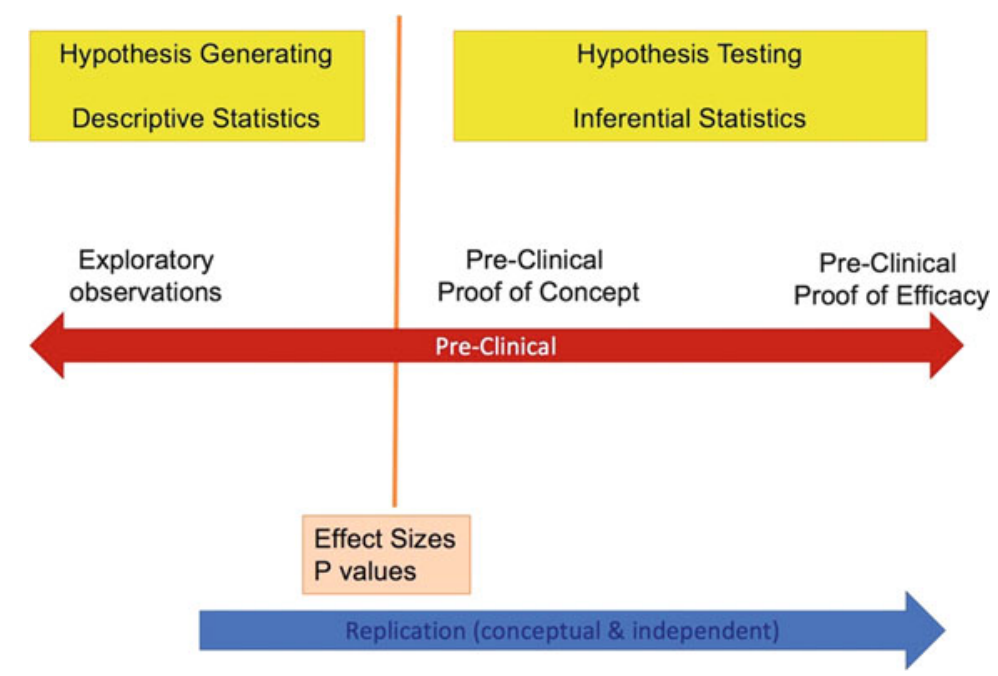

Fig. 1 Comparison of exploratory (hypothesis generating) and confirmatory (hypothesis testing) preclinical studies. Descriptive statistics describes data and provides descriptions of the population, using numerical calculations, graphs, and tables. In contrast, inferential statistics predicts and infers about a population using a sample of data from the population, therefore one can take data from samples and make generalisation about a population

address the issue of design principles for hypothesis-generating studies at the end of this chapter. We advise that when researchers design and conduct hypothesis testing in vivo studies, they should conform to the general principles for the major domains that are outlined in Sect. 4 of the chapter and incorporate these principles into a protocol that can be registered and published. The purpose of using these principles is to enhance scientific rigour without restricting creativity. It is advisable that sometimes there can be exploratory elements within the same hypothesis testing studies; therefore, extra care in terms of applying these principles to reduce experimental biases would be needed before the start of the studies. This chapter will not cover reporting, which will be detailed in chapters "Minimum Information and Quality Standards for Conducting, Reporting, and Organizing In Vitro Research", "Minimum Information in In Vivo Research", and "Quality Governance in Biomedical Research" of the handbook.

We would recommend that researchers who conduct hypothesis testing in vivo studies should prepare clear protocols, which include a statistical analysis plan, detailing how they are going to set up measures to address the major domains of experimental biases before the experiments start. Ideally, these protocols should be preregistered and/or published, so that the methods which will be used to reduce the impact of bias are documented in an a priori fashion. The process of peer review of a protocol prior to initiating experiments of course is a valuable opportunity for refinement and improvement. Registering protocols encourages rigour and transparency, even if the protocol is not peer-reviewed. Some journals are open to submissions of these types of protocols, such as BMJ Open Science, and many journals offer the Registered Reports format. In addition, there are online resources 
that allow researchers to preregister their experimental protocols, such as preclinical. eu and osf.io/registries.

\section{General Scientific Methods for Designing In Vivo Experiments}

Designing an in vivo experiment involves taking a number of decisions on different aspects of the experimental plan. Typically, a comparative experiment can be broken into several component parts.

\subsection{Hypotheses and Effect Size}

The objective is usually to test a hypothesis. On some occasions, two hypotheses may be postulated: the null hypothesis and the alternative hypothesis. The alternative hypothesis refers to the presumption that the experimental manipulation has an effect on the response measured; the null hypothesis is the hypothesis of no change, or no effect. In a statistical test, the $p$-value reports the probability of observing an effect as large or larger than the one being observed if the null hypothesis was true; the smaller the $p$-value, the least likely it is that the null hypothesis is true. The null hypothesis cannot be accepted or proven true. This also defines the effect of interest, i.e. the outcome that will be measured to test the hypothesis. The minimum effect size is the smallest effect the researcher designs the experiment to be able to detect and should be declared in the protocol; it is set up as the minimum difference which would be of biological relevance. The effect size is then used in the sample size calculation to ensure that the experiment is powered to detect only meaningful effects and does not generate statistically significant results that are not biologically relevant. In many cases, it will be hard to determine the minimum difference of biological relevance as for early stage experiments it might be completely unknown, or translatability between clinical relevance and experimental detection thresholds will be complex. There is no simple and easy answer to this question, but in general, a minimum effect size should be set so one can assume to have a beneficial effect for individuals rather than large cohorts, the difference must be experimentally testable and reasonable to achieve, and should have a rationale for translation into patients in the long run.

\subsection{Groups, Experimental Unit and Sample Size}

In comparative experiments, animals are split into groups, and each group is subjected to different interventions, such as a drug or vehicle injection, or a surgical procedure. The sample size is the number of experimental units per group; identifying the experimental unit underpins the reliability of the experiment, but it is often incorrectly identified (Lazic et al. 2018). The experimental unit is the entity 
subjected to an intervention independently of all other units; it must be possible to assign any two experimental units to different comparison groups. For example, if the treatment is applied to individual mice by injection, the experimental unit may be the animal, in which case the number of experimental units per group and the number of animals per group is the same. However, if there is any contamination between mice within a cage, the treatment given to one mouse might influence other mice in that cage, and it would be more appropriate to subject all mice in one cage to the same treatment and treat the cage as the experimental unit. In another example, if the treatment is added to the water in a fish tank, two fish in the same tank cannot receive different treatments; thus the experimental unit is the tank, and the sample size is the number of tanks per group. Once identified, experimental units are allocated to the different comparison groups of the desired sample size; this is done using an appropriate method of randomisation to prevent selection bias (see Sect. 3). Each comparison group will be subjected to different interventions, at least one of which will be a control. The purpose of the control group is to allow the researcher to investigate the effect of a treatment and distinguish it from other confounding experimental effects. It is therefore crucial that any control group is treated exactly in the same way as the other comparison groups. Types of control group to consider include negative control, vehicle control, positive control, sham control, comparative control and naïve control (Bate and Clark 2014).

\subsection{Measurements and Outcome Measures}

Measurements are taken to assess the results; these are recorded as outcome measures (also known as dependent variable). A number of outcome measures can be recorded in a single experiment, for example, if burrowing behaviour is measured, the outcome measure might be the weight of gravel displaced, or if neuronal density is measured from histological brain slides, the outcome measure might be the neuron count. The primary outcome measure should be identified in the planning stage of the experiment and stated in the protocol; it is the outcome of greatest importance, which will answer the main experimental question. The number of animals in the experiment is determined by the power needed to detect a difference in the primary outcome measure. A hypothesis testing experiment may also include additional outcome measures, i.e. secondary outcome measures, which can be used to generate hypotheses for follow-up experiments. Secondary outcome measures cannot be used to draw conclusions about the experiment if the experiment was not powered to detect a minimum difference for these outcome measures.

For the purpose of the statistical analysis, outcome measures fall into two broad categories: continuous or categorical. Continuous measures are sometimes referred to as quantitative data and are measured on a numerical scale. Continuous measures include truly continuous data but also discrete data. Examples of true continuous data include bodyweight, body temperature, blood/CSF concentration or time to event, while examples of discrete data include litter size, number of correct response or clinical score. Categorical responses are measured on a nonnumerical scale; they 
can be ordinal (e.g. severity score, mild/moderate/severe), nominal (e.g. behavioural response, left/middle/right arm maze) or binary (e.g. disease state, present/absent). Continuous responses may take longer to measure, but they contain more information. If possible, it is preferable to measure a continuous rather than categorical response because continuous data can be analysed using the parametric analyses, which have higher power; this reduces the sample size needed (Bate and Clark 2014).

\subsection{Independent Variables and Analysis}

There are many ways to analyse data from in vivo experiments; the first step in devising the analysis plan is to identify the independent variables. There can be two broad types: independent variables of interest which the researcher specifically manipulates to test the hypothesis, for example, a drug with different doses, and nuisance variables, which are other sources of variability that may impact on the outcome measure, but are not of direct interest to the researcher. Examples of nuisance variables could be the day of the experiment, if animals used on different days, or baseline body weight or locomotor activity. Every experiment has nuisance variables. Identifying them at the protocol stage and accounting for them in the design and the analysis, for example, as blocking factors, or co-variables, increase the sensitivity of the experiment to detect changes induced by the independent variable(s) of interest. The analysis plan should be established before the experiment starts and any data is collected; it should also be included in the protocol. Additional analyses can be performed on the data, but if an analysis was not planned before the data was collected, it should be clearly reported as a post hoc or exploratory analysis. Exploratory analyses are at greater risk of yielding false positive results.

\section{Experimental Biases: Definitions and Methods to Reduce Them}

For any researcher who intends to carry out preclinical in vivo studies, it is important to understand what experimental biases are. First, we need to know the definition of bias. It is the inadequacies in the design, conduct, analysis or reporting of an experiment that cause systematic distortion of the estimated intervention effect away from the "truth" (Altman et al. 2001; van der Worp et al. 2010), and it will significantly confound in vivo studies and reduce their internal validity. Sources of bias are multiple and in many cases context dependant. In this overview chapter, it is not possible to give an exhaustive list of potential sources of bias, and it behoves the researcher to systematically identify all potential significant sources of bias for the particular experiment being in planned and to design appropriate mitigation tactics into the protocol. Major known types of biases include selection bias, performance bias, detection bias, and attrition bias. Table 1 gives the definition of each type of bias and describe the methods to reduce them. 
Table 1 Bias definition and bias-reducing methods (Lazic et al. 2018)

\begin{tabular}{|c|c|c|}
\hline Name of bias & Definition of bias & Methods to reduce bias \\
\hline $\begin{array}{l}\text { Selection } \\
\text { bias }\end{array}$ & $\begin{array}{l}\text { Refers to the biased allocation of } \\
\text { animals to different treatment groups, } \\
\text { which could happen at the beginning } \\
\text { of an animal study or at a stage where } \\
\text { reassigning animals to different } \\
\text { treatment groups is needed following } \\
\text { an initial surgical procedure or } \\
\text { treatment. Selection bias results in } \\
\text { systematic differences in baseline } \\
\text { characteristics between treatment } \\
\text { groups (Higgins et al. 2011) }\end{array}$ & $\begin{array}{l}\text { To avoid systematic differences } \\
\text { between animals allocated to different } \\
\text { treatment groups, one shall use a valid } \\
\text { randomisation method, e.g. a } \\
\text { randomisation software or even a } \\
\text { simple method such as picking a } \\
\text { number from a hat (Baastrup et al. } \\
\text { 2010; Huang et al. 2013; Saghaei } \\
\text { 2004). Detail for randomisation is } \\
\text { covered in chapter "Blinding and } \\
\text { Randomization". Note that it is also } \\
\text { necessary to conceal the allocation } \\
\text { sequence from experimenters who } \\
\text { will assign animals to treatment } \\
\text { groups until the time of assignment }\end{array}$ \\
\hline $\begin{array}{l}\text { Performance } \\
\text { bias }\end{array}$ & $\begin{array}{l}\text { Related to the systematic differences } \\
\text { in the care that is provided between } \\
\text { different treatment groups or being } \\
\text { exposed to factors other than the } \\
\text { treatment that could influence the } \\
\text { performance of the animals (Higgins } \\
\text { et al. 2011; O'Connor and Sargeant } \\
\text { 2014; van der Worp et al. 2010). } \\
\text { Performance bias is a result of animals } \\
\text { being managed differently due to, } \\
\text { e.g. housing conditions, diet, group } \\
\text { sizes per cage, location in the animal } \\
\text { house, and experimenters who } \\
\text { provide the care to animals are not } \\
\text { blinded to treatment groups }\end{array}$ & $\begin{array}{l}\text { One can avoid performance bias by } \\
\text { improving the study design, } \\
\text { e.g. applying the same housing, diet, } \\
\text { location conditions to all the animals } \\
\text { and by ensuring proper blinding of the } \\
\text { experimenters to treatment groups, } \\
\text { which keeps the experimenters who } \\
\text { perform the experiment, collect data } \\
\text { and access outcomes unaware of } \\
\text { treatment allocation. Detail for } \\
\text { blinding is covered in chapter } \\
\text { "Blinding and Randomization" }\end{array}$ \\
\hline $\begin{array}{l}\text { Detection } \\
\text { bias }\end{array}$ & $\begin{array}{l}\text { Defined as the systematic distortion of } \\
\text { the results of a study that occurs when } \\
\text { the experimenter assessing } \\
\text { behavioural outcome measures has the } \\
\text { knowledge of treatment assignment to } \\
\text { groups (van der Worp et al. 2010). In } \\
\text { this circumstance, experimenters } \\
\text { measuring the outcomes may } \\
\text { introduce differential measurement of } \\
\text { the outcomes rather than the treatment } \\
\text { itself due to inadvertent expectation }\end{array}$ & $\begin{array}{l}\text { The only way to avoid detection bias } \\
\text { is a complete blinding of the } \\
\text { experimenters, including those who } \\
\text { analyse the data, so that they are not } \\
\text { aware which animal(s) belong to } \\
\text { which treatment group(s). The } \\
\text { protocol should define at what stage } \\
\text { the blinding codes will be broken } \\
\text { (preferably only after data analysis has } \\
\text { been completed). Detail for blinding is } \\
\text { covered in chapter "Blinding and } \\
\text { Randomization" }\end{array}$ \\
\hline Attrition bias & $\begin{array}{l}\text { Is the unequal occurrence and } \\
\text { handling of deviations from protocol } \\
\text { and loss to follow-up between } \\
\text { treatment groups (van der Worp et al. } \\
\text { 2010). This bias can occur when } \\
\text { animals die or are removed from the } \\
\text { study due to adverse effects of the } \\
\text { treatment or pre-set criteria for }\end{array}$ & $\begin{array}{l}\text { Experimenters should report attrition } \\
\text { information for each experimental } \\
\text { group and also include outcomes that } \\
\text { will not be affected by attrition. It is } \\
\text { also advisable to consult a statistician } \\
\text { to minimise the impact of attrition bias } \\
\text { using some statistical approaches such } \\
\text { as intention-to-treat analysis by }\end{array}$ \\
\hline
\end{tabular}


Table 1 (continued)

\begin{tabular}{l|l|l}
\hline Name of bias & Definition of bias & Methods to reduce bias \\
\hline & $\begin{array}{l}\text { removal before observing the } \\
\text { outcomes; therefore, the outcomes are } \\
\text { not observed for all animals, causing } \\
\text { inadvertent bias (O'Connor and } \\
\text { Sargeant 2014) }\end{array}$ & $\begin{array}{l}\text { imputing the missing data. Excluding } \\
\text { "outliers" from analysis should be } \\
\text { only undertaken as an extremely } \\
\text { measure and should only be done to } \\
\text { pre-stated criteria. Detail for statistics } \\
\text { is covered in chapter "Blinding and } \\
\text { Randomization" }\end{array}$ \\
\end{tabular}

Researchers who conduct hypothesis testing in vivo animal work should understand the importance of limiting the impact of experimental biases in the design, conduct, analysis and reporting of in vivo experiments. Experimental biases can cause significant weakness in the design, conduct and analysis of in vivo animal studies, which can produce misleading results and waste valuable resources. In biomedical research, many effects of interventions are fairly small, and small effects therefore are difficult to distinguish from experimental biases (Ioannidis et al. 2014). Evidence (1960-2012 from PubMed) shows that adequate steps to reduce biases, e.g. blinded assessment of outcome and randomisation, have not been taken in more than $20 \%$ and $50 \%$ of biomedical studies, respectively, leading to inflated estimates of effectiveness, e.g. in the fields of preclinical stroke, multiple sclerosis, Parkinson's disease, bone cancer pain and myocardial infarction research (Currie et al. 2013; Macleod et al. 2008; Rooke et al. 2011; Sena et al. 2007; van Hout et al. 2016; Vesterinen et al. 2010) and consequently significant research waste (Ioannidis et al. 2014; Macleod et al. 2014, 2015). Therefore, it is imperative that biomedical researchers should spend efforts on improvements in the quality of their studies using the methods described in this chapter to reduce experimental biases which will lead to increased effect-to-bias ratio.

However, it is worth pointing out that the notion that experimental biases could significantly impact on in vivo animal studies is often assumed because they are believed to be important in clinical research. Therefore, such an assumption may be flawed, as the body of evidence showing the importance of bias-reducing methods such as randomisation, blinding, etc. for animal studies is still limited and most of the evidence is indirect. Furthermore, there may also be sources of bias which impact on preclinical studies which are currently unknown. Thus, systematic review and metaanalysis of in vivo studies have shown that papers that do not report bias-reducing methods report larger effect sizes (Vesterinen et al. 2010). However, these studies are based on reported data alone, and therefore there might be a difference between what researchers do and what they report in their publications (Reichlin et al. 2016). Reporting of the precise details of bias reduction methods is often scanty, and therefore accurate assessment of the precise method and rigour of such procedures is challenging. Moreover, those papers that do not report one bias-reducing method, e.g. randomisation, also tend to not report other bias-reducing methods, e.g. blinding and sample size calculation, suggesting that there could be interactions between these methods. 


\section{$4 \quad$ Experimental Biases: Major Domains and General Principles}

In this section, we will describe the major domains, in other words, sources that could contribute to experimental bias if not carefully considered and if mitigating tactics are not included in the design of hypothesis testing experiments before data collection starts. These include sample size estimation, randomisation, allocation concealment, blinding, primary and secondary outcome measures and inclusion/ exclusion criteria. General descriptions for these domains (Macleod et al. 2009; Rice et al. 2008; Rice 2010; van der Worp et al. 2010) are shown in the following Table 2. It is important to note that these domains are key things to be included in a protocol as mentioned in Sect. 1.

Table 2 General descriptions for the major domains that contribute to experimental biases

\begin{tabular}{l|l}
\hline Major domains & General descriptions \\
\hline Sample size estimation & $\begin{array}{l}\text { The sample size refers to the number of experimental units (e.g. a } \\
\text { single animal, a cage of animals) per group. In hypothesis testing } \\
\text { experiments, it should be determined with a power calculation. } \\
\text { Studies that are not appropriately powered are unethical, and both } \\
\text { underpowered and overpowered studies lead to a waste of } \\
\text { animals. The former because they produce unreliable results and } \\
\text { the latter because they use more animals than necessary }\end{array}$ \\
\hline Randomisation & $\begin{array}{l}\text { Refers to the steps to reduce systematic differences between } \\
\text { comparison groups. Failure to conduct randomisation leads to } \\
\text { selection bias }\end{array}$ \\
\hline Allocation concealment & $\begin{array}{l}\text { Refers to the practice of concealment of the group or treatment } \\
\text { assignment (i.e. the allocation) and its sequence of each } \\
\text { experimental unit from the experimenter until the time of } \\
\text { assignment. Failure to conceal allocation will lead to selection } \\
\text { bias. This should not be confused with randomisation }\end{array}$ \\
\hline Blinding & $\begin{array}{l}\text { Refers to the practice of preventing the experimenter who } \\
\text { administer treatments, take care of the animals, assess the } \\
\text { responses and analyse data from knowing the test condition. } \\
\text { Failure of appropriate blinding leads to selection, performance } \\
\text { and detection biases }\end{array}$ \\
\hline Primary and secondary & $\begin{array}{l}\text { Primary outcome measure refers to the outcome measure of most } \\
\text { interest, and it is related to the efficacy of an intervention that has } \\
\text { the greatest importance for a given study. Secondary outcome } \\
\text { measure refers to the outcome measure that is related to } \\
\text { intervention efficacy but with less importance than the primary } \\
\text { outcome measure and is used to evaluate additional intervention } \\
\text { effects. It is important to declare what intervention effects are in } \\
\text { the study protocol }\end{array}$ \\
\hline $\begin{array}{l}\text { Refers to criteria by which animals will be included or excluded } \\
\text { in a given study, e.g. due to abnormal baselines or not reaching } \\
\text { the required change in thresholds after designed experimental } \\
\text { insult }\end{array}$ \\
\hline Inclusion/exclusion criteria
\end{tabular}


Table 3 General principles to prevent experimental biases in hypothesis testing in vivo studies

\begin{tabular}{|c|c|}
\hline Major domains & General principles \\
\hline Sample size estimation & $\begin{array}{l}\text { A power calculation (desired power of at least } 0.8 \text {, and } \\
\text { alpha }=0.05 \text { ) to estimate the experimental group size should be } \\
\text { carried out before any hypothesis testing study using pilot data or } \\
\text { those relevant data from the literature. This could be done by } \\
\text { using a statistical software. Detail on this can be found in chapter } \\
\text { "A Reckless Guide to P-Values: Local Evidence, Global Errors" }\end{array}$ \\
\hline Randomisation & $\begin{array}{l}\text { There are different methods available to randomly allocate } \\
\text { animals to experimental groups such as computer-generated } \\
\text { randomisation. One should always consider to use the most } \\
\text { robust, appropriate and available method for randomisation. } \\
\text { Detail on this can be found in chapter "Blinding and } \\
\text { Randomization" }\end{array}$ \\
\hline Allocation concealment & $\begin{array}{l}\text { Methods should be used to conceal the implementation of the } \\
\text { random allocation sequence (e.g. numbered cages) until } \\
\text { interventions are assigned, so that the sequence will not be known } \\
\text { or predictable in advance by the experimenters involved in } \\
\text { allocating animals to the treatment groups }\end{array}$ \\
\hline Blinding & $\begin{array}{l}\text { Blinding procedures should be carried out, so that the treatment } \\
\text { identity should not be disclosed until after the outcome } \\
\text { assessments have been finished for all animals and the primary } \\
\text { analysis have been completed. In case that one experimenter } \\
\text { conducts the whole study, any additional steps should be taken to } \\
\text { preserve the blinding. Detail on this can be found in chapter } \\
\text { "Blinding and Randomization" }\end{array}$ \\
\hline $\begin{array}{l}\text { Primary and secondary } \\
\text { outcome measures }\end{array}$ & $\begin{array}{l}\text { Experimenters should decide the outcome of great importance } \\
\text { regarding the treatment efficacy before any study starts as the } \\
\text { primary outcome measure. This is also usually used in the sample } \\
\text { size estimation. Primary outcome measure cannot be changed } \\
\text { once the study starts and when the results are known. } \\
\text { Experimenters should also include secondary outcome measures } \\
\text { relating to additional effects of treatments; these may be used for } \\
\text { new hypothesis generating }\end{array}$ \\
\hline Inclusion/exclusion criteria & $\begin{array}{l}\text { Experimenters should set up the exact criteria which will include } \\
\text { and exclude animals from their studies. Every animal should be } \\
\text { accounted for, except under these criteria. They should be } \\
\text { determined appropriately according to the study nature before the } \\
\text { studies commence. Once determined, they cannot be changed } \\
\text { during the course of investigation }\end{array}$ \\
\hline
\end{tabular}

General principles to reduce experimental bias in each of the above-mentioned domains (Andrews et al. 2016; Knopp et al. 2015) are outlined in the following Table 3. 


\section{Existing Guidelines and How to Use Them}

There are resources to assist investigators in designing rigorous protocols and identify sources of bias. Cross-referencing to experimental reporting guidelines and checklists (e.g. ARRIVE (NC3Rs 2018a), the NIH guidelines (NIH 2018a) and the Nature reporting of animal studies checklist (Nature 2013)) can be informative and helpful when planning an experimental protocol. However, it is important to bear in mind that these are primarily designed for reporting purposes and are not specifically designed for use in assisting with experimental design. There are more comprehensive planning guidelines specifically aiming at early experimental design stage. Henderson et al. identified 26 guidelines for in vivo experiments in animals in 2012 (Henderson et al. 2013) (and a few more have been published since, like PREPARE (Smith et al. 2018), developed by the NORECEPA (Norway's National Consensus Platform for the advancement of the 3Rs), and PPRECISE for the field of pain research (Andrews et al. 2016)). Most of them have been developed for a specific research field but carry ideas and principles that can be transferred to all forms of in vivo experiments. Notable are, for example, the very detailed Lambeth Conventions (Curtis et al. 2013) (developed for cardiac arrhythmia research), from Alzheimer's research recommendations by Shineman et al. (2011) and generally applicable call by Landis et al. (2012).

The authors of many of these guidelines state that their list might need adaption to the specific experiment. This is pointing out the general shortcoming that a fixeditem list can hardly foresee and account for any possible experimental situation and a blind ticking of boxes ticking of boxes is unlikely to improve experimental design. Such guidelines rather serve an educational purpose of making researchers aware of possible pitfalls and biases before the experimental conduct.

Two examples for a more adaptive and reactive way to serve a similar purpose should be stated: the NIH pages on rigour and reproducibility (NIH 2018b) provide in-depth information and collect important publications and workshop updates on these topics and have a funding scheme specifically for rigour and reproducibility. Second, using the Experimental Design Assistant (EDA) (NC3Rs 2018b; Percie du Sert et al. 2017) developed by the UK's National Centre for the 3Rs (NC3Rs), a free to use online platform guiding researchers through experimental planning will give researchers the opportunity to adopt guideline and rigour principles precisely to their needs. The researcher creates a flow diagram of their experimental set-up grouped in three domains: the experiment (general questions on hypotheses and aims, animals used, animal strains, etc.), the practical steps (experimental conduct, assessment, etc.) and the analysis stage (e.g. outcome measures, statistical methods, data processing). Unlike a fixed checklist, the EDA checks the specific design as presented by the experimenter within the tool using logic algorithms. The user is then faced with the flaws the EDA identified and can adjust their design accordingly. This process can go through multiple rounds, by that forming a dynamic feedback loop educating the researcher and providing more nuanced assistance than a static checklist can.

While this process, however valid, might take time, the following steps of the EDA actively guide researchers through crucial and complex questions of the 
experiment, by suggesting fitting methods of statistical analyses of the experiment and subsequently carrying out sample size calculations. The EDA can then also generate a randomization sequence or compile a report of the planned experiment that can, e.g. be part of a preregistration of the experimental protocol.

\section{$6 \quad$ Exploratory and Confirmatory Research}

It is necessary to understand that there are in general two types of preclinical research, namely, exploratory and confirmatory research, respectively. Figure 1 shows that exploratory studies mainly aim to produce theories regarding the pathophysiology of disease (hypothesis generating), while confirmatory studies seek to reproduce exploratory findings as clearly defined intervention effects in relevant animal models (hypothesis testing). The next chapter will deal with exploratory and confirmatory studies in details. Similar standards of rigour are advisable for both forms of studies; this may be achieved by conforming to the general principles for the major domains that are outlined in Table 2 and incorporating these principles into a protocol that can be registered and published. It is important to note that both exploratory and confirmatory research can be closely linked: sometimes there can be exploratory and confirmatory components within the same studies. For example, a newly generated knockout mouse model is used to examine the effect of knockout on one specific phenotype (hypothesis testing - confirmatory) but may also describe a variety of other phenotypic characteristics as well (hypothesis generating - exploratory). Therefore, extra care in terms of applying these principles to reduce experimental bias would be needed before the commence of the studies. It also worth noting that sometimes it might not be compulsory or necessary to use some of the principles during exploratory studies such as sample size estimation and blinding which are albeit of highest importance in confirmatory research.

However, it is necessary to recognise how hypothesis confirming and hypothesis generating research relate to each other: while confirmatory research can turn into exploratory (e.g. if the findings are contrary to the hypothesis, this can lead to a new hypothesis that can be tested in a separate experiment), under no circumstances exploratory findings should be disseminated as the result of hypothesis confirming research by fitting a hypothesis to your results, i.e. to your $p$-values (often called HARKing $=$ hypothesising after results are known or $p$-hacking $=$ sifting through a multitude of $p$-values to find one below 0.05).

In conclusion, this chapter provides general concepts and principles that are important for the design and conduct of preclinical in vivo experiments, including experimental biases and how to reduce these biases in order to achieve the highest levels of rigour for hypothesis generating research using animals. The chapter should be used in conjunction with other relevant chapters in the handbook such as chapters "Blinding and Randomization", "Minimum Information and Quality Standards for Conducting, Reporting, and Organizing In Vitro Research", "Minimum Information in In Vivo Research", "A Reckless Guide to P-Values: Local Evidence, Global Errors", and "Quality Governance in Biomedical Research". 


\section{References}

Altman DG, Schulz KF, Moher D, Egger M, Davidoff F, Elbourne D, Gotzsche PC, Lang T, Consort G (2001) The revised CONSORT statement for reporting randomized trials: explanation and elaboration. Ann Intern Med 134:663-694

Andrews NA, Latremoliere A, Basbaum AI, Mogil JS, Porreca F, Rice AS, Woolf CJ, Currie GL, Dworkin RH, Eisenach JC, Evans S, Gewandter JS, Gover TD, Handwerker H, Huang W, Iyengar S, Jensen MP, Kennedy JD, Lee N, Levine J, Lidster K, Machin I, McDermott MP, McMahon SB, Price TJ, Ross SE, Scherrer G, Seal RP, Sena ES, Silva E, Stone L, Svensson CI, Turk DC, Whiteside G (2016) Ensuring transparency and minimization of methodologic bias in preclinical pain research: PPRECISE considerations. Pain 157:901-909. https://doi.org/10. 1097/j.pain.0000000000000458

Baastrup C, Maersk-Moller CC, Nyengaard JR, Jensen TS, Finnerup NB (2010) Spinal-, brainstemand cerebrally mediated responses at- and below-level of a spinal cord contusion in rats: evaluation of pain-like behavior. Pain 151:670-679. https://doi.org/10.1016/j.pain.2010.08.024

Bate ST, Clark RA (2014) The design and statistical analysis of animal experiments. Cambridge University Press, Cambridge

Currie GL, Delaney A, Bennett MI, Dickenson AH, Egan KJ, Vesterinen HM, Sena ES, Macleod MR, Colvin LA, Fallon MT (2013) Animal models of bone cancer pain: systematic review and meta-analyses. Pain 154:917-926. https://doi.org/10.1016/j.pain.2013.02.033

Curtis MJ, Hancox JC, Farkas A, Wainwright CL, Stables CL, Saint DA, Clements-Jewery H, Lambiase PD, Billman GE, Janse MJ, Pugsley MK, Ng GA, Roden DM, Camm AJ, Walker MJ (2013) The Lambeth Conventions (II): guidelines for the study of animal and human ventricular and supraventricular arrhythmias. Pharmacol Ther 139:213-248. https://doi.org/10.1016/j. pharmthera.2013.04.008

Henderson VC, Kimmelman J, Fergusson D, Grimshaw JM, Hackam DG (2013) Threats to validity in the design and conduct of preclinical efficacy studies: a systematic review of guidelines for in vivo animal experiments. PLoS Med 10:e1001489. https://doi.org/10.1371/journal.pmed. 1001489

Higgins J, Altman DG, Sterne J (2011) Assessing risk of bias in included studies. In: Higgins J, Green S (eds) Cochrane handbook for systematic reviews of interventions. Wiley, Hoboken

Huang W, Calvo M, Karu K, Olausen HR, Bathgate G, Okuse K, Bennett DL, Rice AS (2013) A clinically relevant rodent model of the HIV antiretroviral drug stavudine induced painful peripheral neuropathy. Pain 154:560-575. https://doi.org/10.1016/j.pain.2012.12.023

Ioannidis JP, Greenland S, Hlatky MA, Khoury MJ, Macleod MR, Moher D, Schulz KF, Tibshirani $\mathrm{R}$ (2014) Increasing value and reducing waste in research design, conduct, and analysis. Lancet 383:166-175. https://doi.org/10.1016/S0140-6736(13)62227-8

Knopp KL, Stenfors C, Baastrup C, Bannon AW, Calvo M, Caspani O, Currie G, Finnerup NB, Huang W, Kennedy JD, Lefevre I, Machin I, Macleod M, Rees H, Rice ASC, Rutten K, Segerdahl M, Serra J, Wodarski R, Berge OG, Treedef RD (2015) Experimental design and reporting standards for improving the internal validity of pre-clinical studies in the field of pain: consensus of the IMI-Europain Consortium. Scand J Pain 7:58-70. https://doi.org/10.1016/j. sjpain.2015.01.006

Landis SC, Amara SG, Asadullah K, Austin CP, Blumenstein R, Bradley EW, Crystal RG, Darnell RB, Ferrante RJ, Fillit H, Finkelstein R, Fisher M, Gendelman HE, Golub RM, Goudreau JL, Gross RA, Gubitz AK, Hesterlee SE, Howells DW, Huguenard J, Kelner K, Koroshetz W, Krainc D, Lazic SE, Levine MS, Macleod MR, McCall JM, Moxley RT 3rd, Narasimhan K, Noble LJ, Perrin S, Porter JD, Steward O, Unger E, Utz U, Silberberg SD (2012) A call for transparent reporting to optimize the predictive value of preclinical research. Nature 490:187-191. https://doi.org/10.1038/nature11556

Lazic SE, Clarke-Williams CJ, Munafo MR (2018) What exactly is ' $N$ ' in cell culture and animal experiments? PLoS Biol 16:e2005282. https://doi.org/10.1371/journal.pbio.2005282 
Macleod MR, van der Worp HB, Sena ES, Howells DW, Dirnagl U, Donnan GA (2008) Evidence for the efficacy of NXY-059 in experimental focal cerebral ischaemia is confounded by study quality. Stroke 39:2824-2829. https://doi.org/10.1161/STROKEAHA.108.515957

Macleod MR, Fisher M, O'Collins V, Sena ES, Dirnagl U, Bath PM, Buchan A, van der Worp HB, Traystman R, Minematsu K, Donnan GA, Howells DW (2009) Good laboratory practice: preventing introduction of bias at the bench. Stroke 40:e50-e52. https://doi.org/10.1161/ STROKEAHA.108.525386

Macleod MR, Michie S, Roberts I, Dirnagl U, Chalmers I, Ioannidis JP, Al-Shahi Salman R, Chan AW, Glasziou P (2014) Biomedical research: increasing value, reducing waste. Lancet 383:101-104. https://doi.org/10.1016/S0140-6736(13)62329-6

Macleod MR, Lawson McLean A, Kyriakopoulou A, Serghiou S, de Wilde A, Sherratt N, Hirst T, Hemblade R, Bahor Z, Nunes-Fonseca C, Potluru A, Thomson A, Baginskaite J, Egan K, Vesterinen H, Currie GL, Churilov L, Howells DW, Sena ES (2015) Risk of bias in reports of in vivo research: a focus for improvement. PLoS Biol 13:e1002273. https://doi.org/10.1371/ journal.pbio. 1002273

Nature (2013) Enhancing reproducibility. Nat Methods 10(5):367. https://www.nature.com/articles/ nmeth. 2471

NC3Rs (2018a) ARRIVE guidelines. https://www.nc3rs.org.uk/arrive-guidelines. Accessed 20 Dec 2018

NC3Rs (2018b) The experimental design assistant. https://eda.nc3rs.org.uk. Accessed 20 Dec 2018

NIH (2018a) Principles and guidelines for reporting preclinical research. https://www.nih. gov/research-training/rigor-reproducibility/principles-guidelines-reporting-preclinical-research. Accessed 20 Dec 2018

NIH (2018b) Rigor and reproducibility. https://www.nih.gov/research-training/rigor-reproducibil ity. Accessed 20 Dec 2018

O'Connor AM, Sargeant JM (2014) Critical appraisal of studies using laboratory animal models. ILAR J 55:405-417. https://doi.org/10.1093/ilar/ilu038

Percie du Sert N, Bamsey I, Bate ST, Berdoy M, Clark RA, Cuthill I, Fry D, Karp NA, Macleod M, Moon L, Stanford SC, Lings B (2017) The experimental design assistant. PLoS Biol 15: e2003779. https://doi.org/10.1371/journal.pbio.2003779

Reichlin TS, Vogt L, Wurbel H (2016) The researchers' view of scientific rigor-survey on the conduct and reporting of in vivo research. PLoS One 11:e0165999. https://doi.org/10.1371/ journal.pone.0165999

Rice ASC (2010) Predicting analgesic efficacy from animal models of peripheral neuropathy and nerve injury: a critical view from the clinic. In: Mogil JS (ed) Pain 2010 - an updated review: refresher course syllabus. IASP Press, Seattle, pp 1-12

Rice AS, Cimino-Brown D, Eisenach JC, Kontinen VK, Lacroix-Fralish ML, Machin I, Preclinical Pain C, Mogil JS, Stohr T (2008) Animal models and the prediction of efficacy in clinical trials of analgesic drugs: a critical appraisal and call for uniform reporting standards. Pain 139:243-247. https://doi.org/10.1016/j.pain.2008.08.017

Rooke ED, Vesterinen HM, Sena ES, Egan KJ, Macleod MR (2011) Dopamine agonists in animal models of Parkinson's disease: a systematic review and meta-analysis. Parkinsonism Relat Disord 17:313-320. https://doi.org/10.1016/j.parkreldis.2011.02.010

Saghaei M (2004) Random allocation software for parallel group randomized trials. BMC Med Res Methodol 4:26. https://doi.org/10.1186/1471-2288-4-26

Sena E, van der Worp HB, Howells D, Macleod M (2007) How can we improve the pre-clinical development of drugs for stroke? Trends Neurosci 30:433-439. https://doi.org/10.1016/j.tins. 2007.06.009

Shineman DW, Basi GS, Bizon JL, Colton CA, Greenberg BD, Hollister BA, Lincecum J, Leblanc GG, Lee LB, Luo F, Morgan D, Morse I, Refolo LM, Riddell DR, Scearce-Levie K, Sweeney P, Yrjanheikki J, Fillit HM (2011) Accelerating drug discovery for Alzheimer's disease: best practices for preclinical animal studies. Alzheimers Res Ther 3:28. https://doi.org/10.1186/ alzrt90 
Smith AJ, Clutton RE, Lilley E, Hansen KEA, Brattelid T (2018) PREPARE: guidelines for planning animal research and testing. Lab Anim 52:135-141. https://doi.org/10.1177/ 0023677217724823

van der Worp HB, Howells DW, Sena ES, Porritt MJ, Rewell S, O'Collins V, Macleod MR (2010) Can animal models of disease reliably inform human studies? PLoS Med 7:e1000245. https:// doi.org/10.1371/journal.pmed.1000245

van Hout GP, Jansen of Lorkeers SJ, Wever KE, Sena ES, Kouwenberg LH, van Solinge WW, Macleod MR, Doevendans PA, Pasterkamp G, Chamuleau SA, Hoefer IE (2016) Translational failure of anti-inflammatory compounds for myocardial infarction: a meta-analysis of large animal models. Cardiovasc Res 109:240-248. https://doi.org/10.1093/cvr/cvv239

Vesterinen HM, Sena ES, ffrench-Constant C, Williams A, Chandran S, Macleod MR (2010) Improving the translational hit of experimental treatments in multiple sclerosis. Mult Scler 16:1044-1055. https://doi.org/10.1177/1352458510379612

Open Access This chapter is licensed under the terms of the Creative Commons Attribution 4.0 International License (http://creativecommons.org/licenses/by/4.0/), which permits use, sharing, adaptation, distribution and reproduction in any medium or format, as long as you give appropriate credit to the original author(s) and the source, provide a link to the Creative Commons licence and indicate if changes were made.

The images or other third party material in this chapter are included in the chapter's Creative Commons licence, unless indicated otherwise in a credit line to the material. If material is not included in the chapter's Creative Commons licence and your intended use is not permitted by statutory regulation or exceeds the permitted use, you will need to obtain permission directly from the copyright holder. 